\title{
ASSESSING THE VALUE OF THE INTRODUCTORY COMPUTER CONCEPTS COURSE: 2004 TO 2013
}

\author{
John N. Dyer, Georgia Southern University, jdyer@georgiasouthern.edu \\ Ron MacKinnon, Georgia Southern University,rmackinn@georgiasouthern.edu \\ Hyo-Joo Han, Georgia Southern University,hhan@georgiasouthern.edu \\ Kevin Elder, Georgia College \& State University, kevin.elder@gcsu.edu
}

\begin{abstract}
There has been recent discussion regarding the need to teach introductory computer concepts courses at the university level, assuming that students graduating from high school already possess a broad base of knowledge about computers. This paper focuses on a program of research aimed at measuring student knowledge before taking a concepts course, and assessing the value of the introductory computing course in the IS/IT curricula. The first phase of this research stream involves the assessment of prior mastery of computing concepts by students entering the introductory computing concepts course, in 2004 and again in 2013. While considerable variation in the knowledge of entering students is observed, the average student failed to demonstrate acceptable "proficiency" levels in any of 15 computing content area. These results suggest that there is ample opportunity for an introductory course to enhance student knowledge of computing concepts. The second phase of this investigation assesses the extent to which the introductory course succeeds in broadening the breadth and depth of student knowledge of computing concepts. It assesses the extent to which the introductory course assists students in achieving acceptable proficiency levels in each of 15 computing concepts content areas. It also assesses some degree of change that may be observed in the breadth and depth of student knowledge of computing concepts between course entry and course completion.
\end{abstract}

Keywords: Computer literacy, introductory course and computer concepts

\section{INTRODUCTION}

Most universities offer a computer concepts or computer literacy course and this course is often a required course for non-computer or engineering or business students. For many years there has been an ongoing discussion concerning the content of this computer concepts/computer literacy course and recently there have been questions whether there is still a need for such a course since many students graduating from high school should already have this computer knowledge. Engel (1979), Baron (1984), Sloan (1985), Cohen (1987), Peterson (1987), Sellers (1988) were some of the many people concerned with computer literacy 20-40 years ago. More recently there have been articles by Case (2004), Dyer (2004), Hoffman (2005), Werner (2005), Foster (2006), Gupta (2006), Liao (2008), Dednam (2009) and others, discussing various aspects of computer literacy in today's society. Werner (2005), Stiller (2006), Gupta (2006) and Bannerjee (2009) have been concerned with the changes in computer literacy in the light of our rapidly changing technology. Because of all these changes in this technological oriented society, there has been a concern that perhaps a computer concepts/computer literacy course is redundant and should be dropped because first year students should already know about this material. The relegation of the introductory course to prerequisite status by proponents of the IS 2002 Model Curriculum may reflect a growing consensus that its importance has diminished across time.

Debate about the value of the introductory course has been witnessed in the research literature for more than a decade. There is strong evidence that the percentage of students enrolled in university introductory computing courses who completed one or more computing courses in high school is increasing (e.g., Case, MacKinnon, \& Dyer, 2004; Dick, Edmundson, Elliot, \& Tolhurst, 1999). The increasing prevalence of students with high school computing backgrounds has led faculty and administrators at numerous universities to scrutinize the need to continue to offer introductory computing courses. It has also inspired some scholars to focus on larger question of whether there is a continuing need to include computer literacy components in the Information Systems curriculum (e.g. Gordon and Chimi, 1998). IS/IT educators at 


\section{Issues in Information Systems \\ Volume 14, Issue 1, pp.322-330, 2013}

many institutions question the value of continuing to offer a course that may be little more than a review or validation of computing concepts mastered during high school.

The perceived value of the introductory course is also influenced by research findings indicating that today's high school and university students are among the most frequent users of computers and the Internet. Numerous demographic studies indicate that the average individuals in these groups use computers daily, often for multiple hours per day. The importance of such usage frequencies to student performance in computing courses is underscored by investigations whose findings suggest that prior computer use and attitudes about computing technology have a significant impact on student performance in university-level computing courses (e.g. Davis, 1989; Harris, 1993; Henry, Stone \& Pierce, 1995; Papp, 1996). Students with greater knowledge about computers and students who have positive perceptions of computers are more likely to be successful in computing courses than counterparts with less knowledge and/or less positive perceptions. Case et al. (2004) found that frequency of computer use was the only reliable predictor of student scores on a computing concepts proficiency exam; number of high school computing courses and longevity of Internet and computer use (in years) were also examined by these researchers but were not observed to be reliable predictors of scores on the proficiency test.

The educational implications of the introductory students' computing background are not insignificant. As noted by Bialaszewski, Case, and Wood (1996), student familiarity with information technology is likely to affect the teaching methodology used by instructors as well as instructors' academic expectations about their students' ability and readiness to use sophisticated computing tools. Student familiarity and prior experience with such information technologies are likely to raise instructors' expectations for course outcomes; instructional approaches that capitalize on their students' experience and knowledge are more likely to be used in order to increase the overall value of the course's learning experience.

Most instructors of university-level introductory computing courses would agree that their courses' ability to significantly contribute (add value) to the curriculum is either enabled or constrained by their students' incoming knowledge and prior experience with computing technology. If the foundation knowledge of incoming students is strong, introductory course content can be structured in order to add depth and/or breadth to their knowledge. When the knowledge base of incoming students is minimal, instructors are likely to have more modest expectations for course outcomes. In such instances, course content is more likely to focus on ensuring that students leave the course with the minimum knowledge base needed to enter upper-level courses.

The content of the introductory computing course should also be influenced by changing expectations of university stakeholders, especially employers. Ongoing changes in the minimal computing knowledge/skill sets that employers expect new hires to possess should inspire universities to make appropriate adjustments in their curricula and course content. Over time, the minimum level of computing literacy sought by employers has ratcheted upward. Curricula revisions to changing stakeholder expectations logically begin with introductory courses. However, at many institutions the content of introductory computing courses has changed at glacial speeds, if at all.

\section{Overview of the Research Program}

The first phase of the research program is directed toward answering the question of whether students have already mastered the major concepts addressed in the course via prior coursework or computer experience. The ability of entering students to demonstrate mastery (proficiency) of course concepts would indicate that the content of the introductory course could add little or nothing to their existing knowledge base. The findings of this first phase assessment for 2004 and 2013 are summarized below.

The second phase of this program of research is designed to systematically assess the extent to which the introductory course contributes to increasing the breadth and/or depth of the prior computing concepts knowledge base of entering students. In essence, it is aimed at assessing the degree to which the introductory computer course is a valuable educational experience, that is, if it adds value. The findings of this second phase assessment for 2004 alone are summarized below. 


\section{Issues in Information Systems \\ Volume 14, Issue 1, pp.322-330, 2013}

The subjects for both phases of the investigation were students enrolled in the introductory computing course at a medium-sized comprehensive university in the southeast U.S. The university profile is approximately $56 \%$ female ( $44 \%$ male); $71 \%$ Caucasian (26\% black), $3 \%$ Asian and other; slightly over three percent of the student body are international students. The demographic profile of students enrolled in the introductory course was generally consistent with the university profile.

\section{Phase I Procedures}

In order to determine the knowledge base of entering students, a knowledge assessment test was administered very early in Spring Semesters 2004 and 2013. This timing was used to minimize the impacts of exposure to course content on assessment test results. Students enrolled in the university's Computer Concepts course were offered the opportunity to earn extra credit by completing a 160-item Computer Literacy Assessment Test during the first week of the semester. The extra credit opportunity was announced during each of the first three class meetings in each section of the course. The exam was placed in the student's course management software (WebCT, 2004 and Folio, 2013). In 2004, more than 800 students were enrolled of which 324 chose to take advantage of this extra credit opportunity. In 2013, 150 out of 194 took the test. It should be noted that enrollments in the course have dropped significantly since 2004 as many majors (e.g., business, geographic information systems, and biology, etc.) are now required to take a different course focusing on spreadsheet and database software, while all other students can elect to take it instead of the concepts course. The computer concepts textbook has changed very little since 2004, wherein most changes are editorial in nature (e.g., rearranging topics and combining chapter material).

The test was administered online during a 120-minute period. The test consisted of 160 multiple-choice questions drawn from the textbook publisher's course question database, formatted as an electronic testing utility in the course management software. Each question had four answer alternatives, A, B, C, or D, and the distribution of correct answers was approximately equal, that is, each letter represented a correct answer approximately $25 \%$ of the time The items on the assessment instrument covered a wide range of concept categories that are commonly addressed in introductory computing courses; it addressed topics spanning 15 concept areas summarized in Table 1 .

As Table 1 illustrates, the number of assessment test items measuring content areas varied, both over each topic area alone as well as from 2004 to 2013. However, it is important to note that the number of questions for each content area was generally proportional to the amount of coverage the content area received in the course and the test as a whole reasonably reflected the degree of attention devoted to each of the different content areas during the semester. It is also important to note that all questions relating to each concept area were not necessarily offered in a structured sequence. For example, the locations of the 10 questions measuring topic area 1 in 2004 were questions $1,2,3,4,8,9,37,39,84$ and 104.

\section{Phase Results}

Overall, both groups scored an average of $46 \%$ on the test, with a standard deviation of $10.1 \%$ in 2004 and $9.6 \%$ in 2013 . The combined score was also $46 \%$ with a standard deviation of $9.7 \%$. For both test groups a test for randomness was performed to determine if the overall test result of $46 \%$ was due to random chance or to other reasons. Under the null hypothesis an overall test result of $25 \%$ was expected, while the observed result of $46 \%$ was significant with $p$-value $=0.0000$. This implies that at least a majority of the students had some basic knowledge of computing concepts beyond that expected if a simple guessing strategy were employed. Additionally, in 2004 each student's complete score was tested for randomness. This indicated that that 58 of the 324 students performed no better than what would be expected by employing a guessing strategy. After removing these 58 students, the overall test result increased to $49 \%$ for the remaining 266 students. This would tend to imply that $18 \%$ (58 of 324) of the sampled students possess one or more of the following characteristics:

(1) Have no broad knowledge of the computing concepts and hence employ a guessing strategy,

(2) Have some basic knowledge of the computing concepts but still choose to employ a guessing strategy, or 
(3) Try to answer each question without employing a guessing strategy but still have no broad knowledge of computing concepts.

(4) Are not taking the assessment seriously or giving a good faith effort to correctly answer the questions.

Since it is debatable whether analysis should be performed on all 324 student tests or only the 266 student tests for which a random guessing strategy can be ruled out, the results provided below include all 324 students to ensure the most conservative results. The analysis of the 2013 tests also uses the full sample of 150 students.

\section{Content Area Analysis}

For 2004 and 2013, an analysis was also performed on each of the separate 15 content areas. Table 1 displays the summary statistics relating to each of the 15 content areas. Most importantly, Table 1 reveals the average percent of individual questions in each content area answered correctly, an indication of if each content area's average percent correct was random or nonrandom, and the percent of questions in each content area that were shown to be nonrandom. For example, in 2004 Chapter 1 contained 10 questions, and the average percent correct of the 10 questions across all 324 responses was $65 \%$, while in 2013 the average was $62 \%$. If a content area's average percent correct value was due entirely to randomness, such as most students using a simple guessing strategy, the expected value would be $25 \%$, hence a null hypothesis that the true proportion is 0.25 . Based on a 0.01 significance level and an upper confidence limit on the proportion ( 0.31 for 2004, 0.34 for 2009), there is strong evidence that students in both years have some knowledge of content area 1 over what would be expected from employing a guessing strategy. It should be noted that one can consider practical significance as well as statistical significance, wherein any content area average even close to the upper confidence limit bound suggests little more than a guessing strategy.

Additionally, the item analysis of the questions relating to Chapter 1 reveal that in $2004,90 \%$ of the 10 questions indicate student performance greater than what would be expected if students were employing a guessing strategy, while in $2013,100 \%$ of questions indicate the same. It should also be noted that the average percent correct value for each content area is similar to an exam score covering the specified content area. As such, it is evident that the sample of students possesses an unacceptable level of proficiency in all of the content areas. While a majority of the content areas (87\%) do show performance at a level above random guessing, content areas 13 and 15 indicate a response pattern that is consistent with random guessing, and areas 8,10 and 14 are suspect. As such, there is no evidence that the sample of students, as a whole, possess any knowledge of these content areas.

Table 1.

\begin{tabular}{|c|c|c|c|c|c|c|}
\hline Chapter & Topic & Year & $\begin{array}{c}\text { \# of } \\
\text { Questions } \\
\end{array}$ & Average & Nonrandom & $\begin{array}{c}\% \text { of } \\
\text { Nonrandom } \\
\text { Questions } \\
\end{array}$ \\
\hline \multirow{2}{*}{1} & \multirow{2}{*}{ Basic Computer Concepts } & 2004 & 10 & $65 \%$ & Yes & $90 \%$ \\
\hline & & 2013 & 8 & $62 \%$ & Yes & $100 \%$ \\
\hline \multirow{2}{*}{2} & \multirow{2}{*}{ The Internet and the World Wide Web } & 2004 & 15 & $49 \%$ & Yes & $67 \%$ \\
\hline & & 2013 & 13 & $59 \%$ & Yes & $92 \%$ \\
\hline \multirow{2}{*}{3} & \multirow{2}{*}{ Application Software } & 2004 & 5 & $50 \%$ & Yes & $83 \%$ \\
\hline & & 2013 & 8 & $54 \%$ & Yes & $88 \%$ \\
\hline \multirow{2}{*}{4} & \multirow{2}{*}{ The Components of the System Unit } & 2004 & 7 & $51 \%$ & Yes & $71 \%$ \\
\hline & & 2013 & 10 & $46 \%$ & Yes & $70 \%$ \\
\hline \multirow{2}{*}{5} & \multirow{2}{*}{ Input } & 2004 & 17 & $52 \%$ & Yes & $65 \%$ \\
\hline & & 2013 & 12 & $53 \%$ & Yes & $75 \%$ \\
\hline \multirow{2}{*}{6} & \multirow{2}{*}{ Output } & 2004 & 8 & $58 \%$ & Yes & $75 \%$ \\
\hline & & 2013 & 9 & $49 \%$ & Yes & $67 \%$ \\
\hline
\end{tabular}


Issues in Information Systems

Volume 14, Issue 1, pp.322-330, 2013

\begin{tabular}{|c|c|c|c|c|c|c|}
\hline \multirow{2}{*}{7} & \multirow{2}{*}{ Storage } & 2004 & 11 & $49 \%$ & Yes & $91 \%$ \\
\hline & & 2013 & 10 & $40 \%$ & Yes & $60 \%$ \\
\hline \multirow{2}{*}{8} & \multirow{2}{*}{$\begin{array}{l}\text { Operating Systems and Utility } \\
\text { Programs }\end{array}$} & 2004 & 13 & $40 \%$ & Yes & $77 \%$ \\
\hline & & 2013 & 10 & $41 \%$ & Yes & $60 \%$ \\
\hline \multirow{2}{*}{9} & \multirow{2}{*}{ Communications and Networks } & 2004 & 9 & $39 \%$ & Yes & $56 \%$ \\
\hline & & 2013 & 13 & $53 \%$ & Yes & $69 \%$ \\
\hline \multirow{2}{*}{10} & \multirow{2}{*}{ Database Management } & 2004 & 11 & $48 \%$ & Yes & $71 \%$ \\
\hline & & 2013 & 11 & $56 \%$ & Yes & $91 \%$ \\
\hline \multirow{2}{*}{11} & \multirow{2}{*}{$\begin{array}{l}\text { Computers and Society, Security, } \\
\text { Privacy and Ethics }\end{array}$} & 2004 & 17 & $50 \%$ & Yes & $71 \%$ \\
\hline & & 2013 & 16 & $57 \%$ & Yes & $69 \%$ \\
\hline \multirow{2}{*}{12} & \multirow{2}{*}{ Information System Development } & 2004 & 9 & $36 \%$ & Yes & $67 \%$ \\
\hline & & 2013 & 11 & $38 \%$ & Yes & $55 \%$ \\
\hline \multirow{2}{*}{13} & \multirow{2}{*}{$\begin{array}{l}\text { Programming Languages and Program } \\
\text { Development }\end{array}$} & 2004 & 11 & $27 \%$ & No & $45 \%$ \\
\hline & & 2013 & 10 & $29 \%$ & No & $30 \%$ \\
\hline \multirow{2}{*}{14} & \multirow{2}{*}{ Enterprise Computing } & 2004 & 10 & $39 \%$ & Yes & $80 \%$ \\
\hline & & 2013 & 10 & $49 \%$ & Yes & $80 \%$ \\
\hline \multirow{2}{*}{15} & \multirow{2}{*}{ Computer Careers and Certification } & 2004 & 7 & $31 \%$ & No & $43 \%$ \\
\hline & & 2013 & 9 & $34 \%$ & No & $33 \%$ \\
\hline
\end{tabular}

Table 2 again displays the average percent correct for each chapter for the $2004(n=324)$ and $2013(n=150)$ samples, the difference in averages, as well as the z-score and p-value testing the difference in the proportion of correct answers between years for each chapter. As mentioned previously, the average difference in overall performance saw no change at $46 \%$ overall in both years. It is interesting to note that Chapter 1 topics received the greatest percent correct of 65\% (2004) and 62\% (2013). Additionally, 14 of the 15 content areas were failed by both groups if considering $60 \%$ as a passing grade. At the .05 significance level there are significant differences between performances in content areas 2, 9 and 14, wherein students in 2013 performed significantly better. It is interesting to note that 2013 students performed more poorly in content areas 6 and 7, with p-values of 0.07 and 0.06 respectively. The result suggests that over the 9 years there is no significant improvement in the computer concepts knowledge of these students, overall and in most content areas.

Table 2.

\begin{tabular}{lccccc}
\hline Topic & $\begin{array}{c}\mathbf{2 0 0 4} \\
\text { Average }\end{array}$ & $\begin{array}{c}\mathbf{2 0 1 3} \\
\text { Average }\end{array}$ & Difference & Z & p-value \\
\hline \hline Basic Computer Concepts & $65 \%$ & $62 \%$ & $-3.4 \%$ & -0.72 & 0.47 \\
\hline The Internet and the World Wide Web & $49 \%$ & $59 \%$ & $10.2 \%$ & 2.06 & $\mathbf{0 . 0 4}$ \\
\hline Application Software & $50 \%$ & $54 \%$ & $3.9 \%$ & 0.79 & 0.43 \\
\hline The Components of the System Unit & $51 \%$ & $46 \%$ & $-5.4 \%$ & -1.10 & 0.27 \\
\hline Input & $52 \%$ & $53 \%$ & $0.9 \%$ & 0.19 & 0.85 \\
\hline Output & $58 \%$ & $49 \%$ & $-8.9 \%$ & -1.81 & 0.07 \\
\hline Storage & $49 \%$ & $40 \%$ & $-9.3 \%$ & -1.88 & 0.06 \\
\hline Operating Systems and Utility Programs & $40 \%$ & $41 \%$ & $1.0 \%$ & 0.21 & 0.83
\end{tabular}


Issues in Information Systems

Volume 14, Issue 1, pp.322-330, 2013

\begin{tabular}{lccccc}
\hline Communications and Networks & $39 \%$ & $53 \%$ & $14.1 \%$ & 2.88 & $\mathbf{0 . 0 0}$ \\
\hline Database Management & $48 \%$ & $56 \%$ & $8.0 \%$ & 1.62 & 0.10 \\
\hline $\begin{array}{l}\text { Computers and Society, Security, Privacy and } \\
\text { Ethics }\end{array}$ & $50 \%$ & $57 \%$ & $7.2 \%$ & 1.47 & 0.14 \\
\hline $\begin{array}{l}\text { Information System Development } \\
\text { Programming Languages and Program }\end{array}$ & $36 \%$ & $38 \%$ & $1.9 \%$ & 0.40 & 0.69 \\
\hline $\begin{array}{l}\text { Development } \\
\text { Enterprise Computing }\end{array}$ & $39 \%$ & $49 \%$ & $10.2 \%$ & 2.08 & 0.04 \\
\hline Computer Careers and Certification & $31 \%$ & $34 \%$ & $3.0 \%$ & 0.65 & 0.52 \\
\hline \hline
\end{tabular}

\section{Phase I Conclusions}

Based on the analysis of the overall assessment test scores, as well as the individual question and content area analysis, the evidence suggests that students entering the introductory course do have some broad knowledge of computer concepts above what is expected with random guessing. This sample of students does not, however, demonstrate an acceptable level of mastery of computer concepts. The students' greatest level of knowledge and proficiency relates to basic computer concepts, particularly terminology and uses of computers, as well as the Internet and the World Wide Web, and hardware elements of the information processing cycle (input, processing, and output). The students' lowest level of proficiency relates to communication and networks, information systems development, programming languages and development, enterprise computing systems, and computer careers.

\section{Phase I Discussion}

The results of the first phase of our investigation suggest that the majority of students enrolling in university-level introductory computing courses do not possess an acceptable level of prior knowledge or experience base to be considered proficient in fundamental computing concepts. These finding argue against the removal of such courses from IS/IT curricula. While the number of students enrolled in such courses who have completed one or more computing courses in high school or who are frequent computer users is increasing, their mastery of fundamental concepts tends to fall short of the minimum levels needed to be considered proficient. In other words, the introductory course may not be superfluous for most of the students that take it.

We suspect that the best explanation for our findings may be that prior coursework tended to focus on keystrokes rather than computing concepts. Many high school courses are applications oriented rather than computing concepts oriented. As a result, students enhance their ability to use particular applications without ever really having to come to grips with how the program works with the operating system and hardware to accomplish user tasks. If high school courses focused more squarely on fundamental computer operations, rather than computer applications, our results may have been very different.

\section{Phase II Procedures}

As noted previously, the second phase of this investigation is designed to assess the extent to which the introductory course contributes to increasing the breadth and/or depth of the prior computing concepts knowledge base of entering students. The same subject pool used for Phase I 2004 was employed in Phase II. In addition, the same assessment test was administered and once again, it was administered online.

As was the case for Phase 1, students in the introductory course were informed of an opportunity to earn extra credit by taking an online assessment test. The extra credit opportunity and was announced during each of the last two weeks of class in each section of the course. Information about the extra credit opportunity and available test times was also placed in each student's course management software. More than half of the students (490) enrolled in the five sections of the course and chose to take advantage of this extra credit opportunity during the last week of Spring Semester 2004; this produced 475 usable responses. 
Several changes to the baseline data provided by the Phase I results should be observed if the introductory course contributes to adding breadth to the students' knowledge base of computing concepts.

- There should be overall improvement in the student scores on the assessment test; students should be able to answer more questions correctly regardless of content area

- There should be a reduction in the number of content areas for which random guessing cannot be ruled out as a response pattern.

- There should be a reduction in the number (and percentage) of students taking the test whose response pattern is consistent with random guessing.

Several changes should also be observed to the baseline statistics provided by the Phase I results if the introductory course contributes to adding depth to the students' knowledge of computing concepts

- The average percentage correct should improve for each content area.

- The percentage of questions in each category with non-random response patterns should increase.

- The number and percentage of students demonstrating acceptable proficiency levels within each content area should increase.

\section{Phase II Results}

Although the randomness tests, question analysis, and content area analysis performed on the data collected during Phase 1 are not used for Phase 2, there is evidence that overall the course is valuable in contributing to a student's core computer concepts. The more limited results of the data collected during Phase II reveal substantial increases in the $25^{\text {th }}, 50^{\text {th }}$, and $75^{\text {th }}$ percentile scores. They also reveal a dramatic jump in the percentage of test takers correctly answering at least 100 of 160 items on the test. Less than $6 \%$ of the students taking the test during Phase I answered 100 or more questions correctly; $19 \%$ of the students participating in Phase II answered at least 100 items correctly.

In addition, the percentage of students exhibiting response patterns consistent with random guessing declined from Phase I to Phase II. As noted previously, $18 \%$ of the Phase I test takers exhibited response patterns consistent with random guessing. Only $9 \%$ of the Phase II test takers exhibited such a pattern.

\section{Phase II Discussion}

The preliminary results suggest that the intervention that occurred between the Phase I and Phase II assessments (the introductory course) may have added breadth and depth to student knowledge of computing concepts. Needless to say, planned analyses must be completed to provide firmer conclusions.

The approach being used has the potential to identify the content areas for which the greatest and least amount of improvement has occurred. It is hoped that the greatest increases in student knowledge will be observed in the content area that incoming students seem to know the least about namely: data communications and networking, information systems development, programming languages and development, enterprise computing systems, and computer careers.

\section{Limitations}

There are several limitations that should not be overlooked when interpreting the results of both phases of the study. One limitation was using the textbook author's unedited "test-out" database as the source of questions. Although the number of questions representing each content area was proportional to content coverage in the course, the instrument may be flawed by an inadequate number of questions for some of the content areas. This can tend to make analysis and comparisons among content areas weak and/or inconclusive. 


\section{Issues in Information Systems \\ Volume 14, Issue 1, pp.322-330, 2013}

Additionally, some of the questions in the database require little more than a common sense approach to be answered correctly, and many others can be guessed with greater likelihood by simply eliminating the obviously wrong answer(s), then guessing from the remaining choices. This situation can lead to biased results that tend to measure a student's common sense and systematic guessing ability instead of content knowledge.

Another limitation of the study is the inability of the investigators to determine how many correct answers are based on knowledge versus common sense and guessing. A more suitable set of questions would not only test specific knowledge of the content by forming questions and correct answers in a way that only a student with exacting detailed knowledge could answer correctly, but to also provide a fifth alternative answer to each question that allows students to indicate that they do not know the answer. This would tend to reduce the effects of common sense answer selection and guessing, and provide results that more accurately measure the student's knowledge of computer concepts.

\section{CONCLUSIONS}

Our findings suggest the student knowledge is strongest in the following content areas upon entry into the introductory course: basic computer concepts (particularly terminology and uses of computers), the Internet and the World Wide Web, and hardware elements of the information processing cycle (input, processing, and output). However, the average incoming student is incapable of correctly answering more than $60 \%$ of the questions asked about these concepts and many educators would have a difficult time accepting that this is an acceptably solid knowledge base.

Although an increasing percentage of students enter college having taken at least one computing course during high school and/or with significant hands-on computer experience, they still may lack the knowledge base needed to be effective consumers or managers of basic computing technologies. Our Phase I findings suggest that this may be so. They also indicate that there is considerable room for improvement. The preliminary results for Phase II of our investigation suggest that the introductory course has the potential to overcome computing knowledge gaps.

Although the introductory course has been relegated to prerequisite status in the IS 2002 Model Curriculum, it may still fulfill an important need at many universities. It may play an especially important role in narrowing the wide diversity in the computing backgrounds of enrolled students. The introductory computing concepts course may also help to ensure that student mastery of computing concepts extends beyond hands-on experience with productivity software applications. It can assist students in becoming more knowledge consumers and managers of information technologies.

\section{REFERENCES}

1. Banerjee, S., Kawashm J. (2009). Re-thinking Computer Literacy in Post-Secondary Education. Proceedings of the $14^{\text {th }}$ Western Canadian Conference on Computing Education, Burnaby, B. C. May 01-02, 2009 R. Brouwer, D. Cukiernab \$ G. Tsknis, Eds WCCCE '09 ACM NYm 17-21, DOI= http://dl.acm.org/citation.cfm?doid=1536274.1536282

2. Bialaszewski, D., Case, T., and Wood, B. (1996). Data Communications: Theoretical and Experimental Instruction Incorporating the Internet. Proceedings of the Eleventh Annual Conference of the International Academy for Information Management, 63-66.

3. Baron, N. S. (1984). Should Everyone Learn Anything?: The Question of Computer Literacy, Proceedings of the Fifteenth SIGCSE Technical Symposium on Computer Science Education L. N. Cassel and J. C. Little, Eds. SIGSCE '84. ACM, New York, NY, 108-114. DOI= http://doi.acm.org/10.1145/800039.808632

4. Case, T., MacKinnon, R. and Dyer, J. (2004). Computer Literacy and the Introductory Student: An Analysis of Perceived and Actual Knowledge of Computers and Computer Applications. Proceedings of the Sixth Annual Conference of the Southern Association for Information Systems, 278-284.

5. Cohen, E. (1987). What is Computer Literacy: the Sham, the Imposter, and the Misdirected, Proceedings of the 15th Annual Conference on Computer Science (St. Louis, Missouri, United States). CSC '87. ACM, New York, NY, 320-322. DOI= http://doi.acm.org/10.1145/322917.322969 
6. Davis, F. D. (1989). Perceived Usefulness, Perceived Ease of Use, and User Acceptance of Information Technology. MIS Quarterly, 13, 319-40.

7. Dednam, E. (2009). Away With Computer Literacy Modules at Universities, Or not?, Proceedings of the 2009 Annual Conference of the Southern African Computer Lecturers' Association (Eastern Cape, South Africa, June 29-July 01, 2009) SACLA, '09. ACM, New York, NY, 23-32, DOI= http://dl.acm.org/citation.cfm?doid=1562741.1562744

8. Dick, G. N., Edmundson, R. H., Elliot, S. R., and Tolhurst, D. (1999). Changing Skills, Changing Demands, Changing Expectations: What Implications for IS Schools? Proceedings of the Fourteenth Annual Conference of the International Academy for Information Management, 274-279.

9. Dyer, J. MacKinnon, R., Case, T. (2004). What Intro Students Know About Computer Concepts, New York, NY: Americas Conference on Information Systems, 2917-2924.

10. Engel, G. L. (1979). The ACM Project on Computers and Society and Computer Literacy Courses and Materials. Proceedings of the 1979 Annual Conference A. L. Martin and J. L. Elshoff, Eds. ACM 79. ACM, New York, NY, 160. DOI= http://doi.acm.org/10.1145/800177.810056

11. Foster, K., DeNoia, L., and Dannelly, S. (2006). Reengineering a Computer Literacy Course. Journal of Computing in Small Colleges. 22, 2 (Dec. 2006), 197-202.

12. Gaber, A. (2004). Conversion: The Benefits and Best Practices of Computer-Based Testing. Retrieved February 22, 2013, from http://www.thefreelibrary.com//print/PrintArticle.aspx?id=132578675

13. Gordon, G. M. and Chimi, C. J. (1998). Should the Introductory Information Systems Course be Removed from the Business School Curriculum? A Preliminary Investigation. Proceedings of the Thirteenth Annual Conference of the International Academy for Information Management, 1-7.

14. Gupta, G. K. (2006). Computer Literacy: Essential in Today's Computer-Centric World. SIGCSE Bull. 38, 2 (Jun. 2006), 115-119. DOI= http://doi.acm.org/10.1145/1138403.1138446

15. Harris, A. L. (1993). The Impact of the Introductory MIS Course on Students' Attitudes and Perceptions Towards Microcomputers. Journal of Computer Information Systems, Winter 1992-1993, $38-41$.

16. Henry, J., Stone, R., and Pierce, M. (1995) Determinants of Student Performance in the Introductory Computer Programming Course in the College of Business. Proceedings of the Tenth Annual Conference of the International Academy for Information Management, 91-104.

17. Hoffman, M. E. and Vance, D. R. (2005). Computer Literacy: What Students Know and From Whom They Learned It. Proceedings of the 36th SIGCSE Technical Symposium on Computer Science Education (St. Louis, Missouri, USA, February 23 - 27, 2005). SIGCSE '05. ACM, New York, NY, 356-360. DOI= http://doi.acm.org/10.1145/1047344.1047467

18. Liao, L. and Pope, J. W. (2008). Computer Literacy for Everyone. Journal of Computing in Small Colleges. 23, 6 (Jun. 2008), 231-238

19. McDonald, D. (2004). Computer Literacy Skills for Computer Information Systems Majors: A Case Study. Journal of Information Systems Education, 15, 19-34.

20. Papp, R. (1996) Student Perception and Knowledge About Information Technology: A Computer Attitude and Experience Survey to Measure Changes. Proceedings of the Eleventh Annual Conference of the International Academy for Information Management, 7-15.

21. Peterson, J. T. (1987). Goals for and Lessons from a Computer Literacy Course. In Proceedings of the Eighteenth SIGCSE Technical Symposium on Computer Science Education (St. Louis, Missouri, United States, February 19 - 20, 1987). A. K. Rigler and D. C. St. Clair, Eds. SIGCSE '87. ACM, New York, NY, 504-507. DOI= http://doi.acm.org/10.1145/31820.31813

22. Sellars, H. L. (1988). Why a College Course in Computer Literacy?. SIGCSE Bull. 20, 2 (Jun. 1988), 58-59. DOI= http://doi.acm.org/10.1145/45202.45216

23. Sloan, L. and Halaris, A. (1985). Towards a Definition of Computing Literacy for the Liberal Arts Environment. Proceedings of the Sixteenth SIGCSE Technical Symposium on Computer Science Education (New Orleans, Louisiana, United States, March 14 - 15, 1985). J. E. Miller, Ed. SIGCSE '85. ACM, New York, NY, 320-326. DOI= http://doi.acm.org/10.1145/323287.323400

24. Stiller, E. and LeBlanc, C. (2006). From Computer Literacy to Cyber-Literacy. Journal of Computing in Small Colleges, 21, 6 (Jun. 2006), 4-13.

25. Werner, L. (2005). Redefining Computer Literacy in the Age of Ubiquitous Computing. Proceedings of the 6th Conference on information Technology Education (Newark, NJ, USA, October 20 - 22, 2005). SIGITE '05. ACM, New York, NY, 95-99. DOI= http://doi.acm.org/10.1145/1095714.1095738 